\title{
Water Management Using System Dynamics Modeling in Semi-arid Regions
}

\author{
Hamid Reza Nassery ${ }^{a}$, Rouhollah Adinehvand ${ }^{\mathrm{b}}$, Abdalrahim Salavitabar ${ }^{\mathrm{c}}$, Reza Barati $^{\mathrm{d} *}$ \\ ${ }^{a}$ College of Earth Sciences, University of Shahid Beheshti, Tehran, Iran. \\ ${ }^{b}$ Department of Earth Sciences, Shiraz University, Shiraz, Iran. \\ ${ }^{b}$ Consultant to Executive Director at Mahab Ghodss Consulting Engineers, Tehran, Iran. \\ ${ }^{b}$ Faculty of Civil \& Environmental Engineering, Tarbiat Modares University, Tehran, Iran.
}

Received 15 July 2017; Accepted 26 September 2017

\begin{abstract}
Quantitative control and safe exploitation of water resources are crucial components for the sustainable development of any region due to increasing water scarcity, especially in arid and semiarid regions. A proper water resources management program of the Tabriz plain is necessary because of the groundwater excessive exploitation and the surface water limitations. The present study aims to develop a system dynamics (SD) model not only to identify safe groundwater level fluctuations and exploitation but also to determine the amount of supply and deficits of municipal-industry and agricultural uses by considering various water management strategies. The integrated water resources including surface and groundwater resources were included in the analyses. The considered alternatives are the development of sewage collection networks, enhancement of agricultural efficiency, climate changes effects, artificial recharge and changes of the allocation of the surface and groundwater in supplying water needs. SD modeling application showed that if the current management policy was continued, the users will face a crisis of the water supply for various uses in the future. Increase in agricultural efficiency, reducing in groundwater extraction and artificial recharge in Tabriz plain must be considered to prevent the crisis. The current model provides a better understanding of the principal challenge of balancing supply and demand with regards to drastic changes of water resources in arid or semiarid regions.
\end{abstract}

Keywords: System Dynamics; Simulation; Sustainable Development; Integrated Water Resources Management; Semiarid; Climate Changes.

\section{Introduction}

Water, like air and food, is our life support. Water resources management is a complicated and delicate subject in the regional planning, managing and development, especially in semiarid regions [1-4]. The water problems arise from both general water shortage and demand mismanagement [5]. Demand management techniques can be applied as an effective approach for solving the latter issue by considering various management alternatives, especially in developing countries.

A system is a set of interactive elements that perform independent of each other to achieve some particular objective through the control and distribution of material resources, energy and information [6]. In complex urban water systems, simulation models can be effectively used for evaluating the performance of existing water policies and developing new policy and operational practices by considering the seasonal and climatic conditions and sustainability development principles to help operators in the proper use of these systems [7].

\footnotetext{
* Corresponding author: r88barati@gmail.com
}

DOI: http://dx.doi.org/10.21859/cej-030913

> This is an open access article under the CC-BY license (https://creativecommons.org/licenses/by/4.0/).

(C) Authors retain all copyrights. 
There are several simulation methodologies to facilitate the evaluation of effective strategies for achieving water resource management objectives with different capabilities, complexity, scale, resolution, and preciseness features. One of these methodologies is the system dynamics modeling, which has been introduced by Forrester [8]. It is a computer simulation procedure developed to understand the performance of complex systems over time and to design alternative solutions by improving our capacity to extrapolate and interpolate in a meaningful manner in a broader context, based on the capturing the underlying structure of the system [9]. SD modeling originated in the management and engineering, but developed as a useful tool for the analysis of the social, ecological, economic, physical, chemical and biological systems [10]. It has also been used for integrating complex hydrologic data with other information (e.g., policy, regulatory, and management criteria) to produce a decision support system [11].

The most important features of this type of simulation modeling are the open design and visual modeling environment along with the ability of the user to exercise the model and test behavior of the system. Cause and effect diagrams are very useful tools for understanding system structure and origin of system behavior patterns. When an element of a system after a delay indirectly affects itself, those parts of the system that are affected called a feedback loop. Every decision is made in a feedback loop that is a closed loop of causes and effects [12]. In a loop, the response of the each element based on whether it has an increase or decrease effect on the variable is shown by (+) or (-) signs (see Figure 1a). Cause and effect diagrams are unable to explain stock and flow structures; therefore stock and flow diagrams are also used (see Figure 1b). Stock and flow along with feedback loops are two essential concepts of the theory of the system dynamics [6].

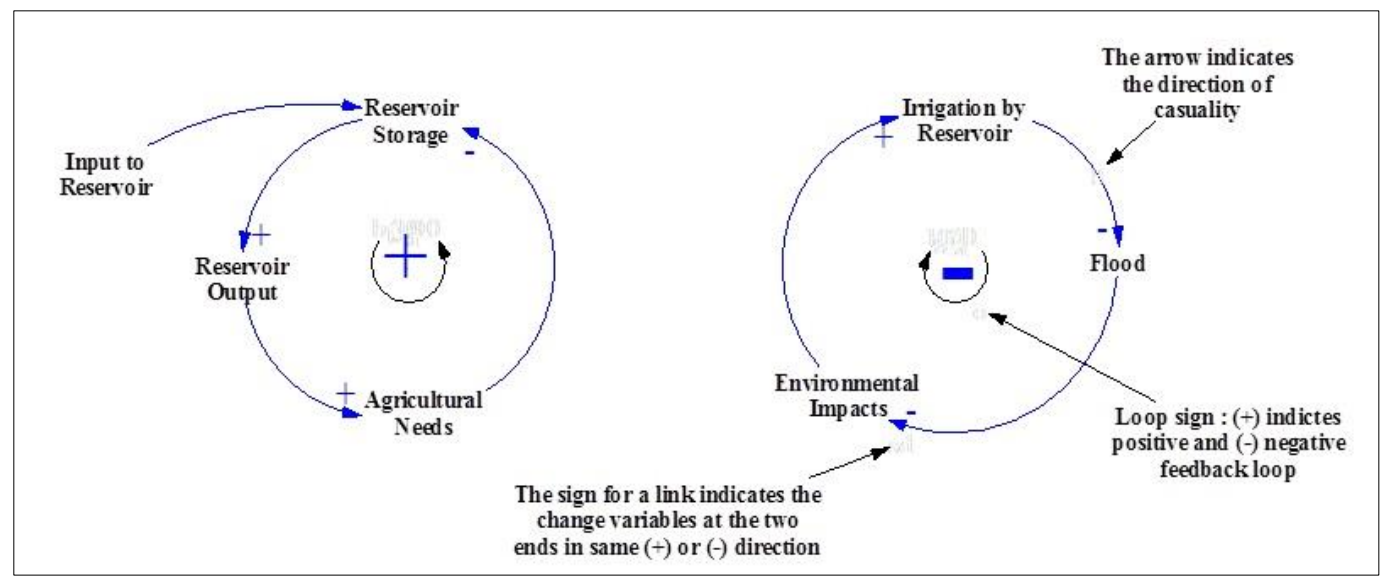

Figure 1a. Cause and effect diagrams for the filling and sinking a reservoir; (+) sign and (-) sign indicating type of the feedback (modified after Simonovic [6]).

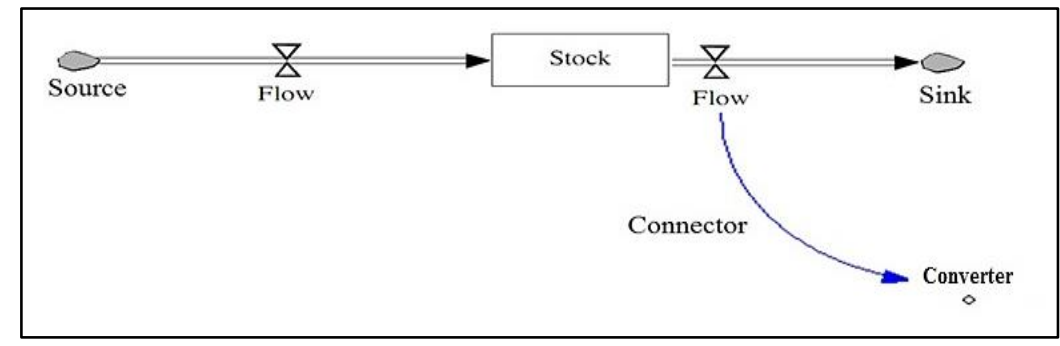

Figure 1b. Symbols used to draw stock and flow diagrams. Rectangles represent stocks which are containers flow values represent system flows in and out of a stock. Converters are calculations within the model. The direction of the arrows shows the causation direction. Clouds indicate that the flow origin or exits outside the scope of the model (modified after Simonovic [6]).

Stave [13] build a strategic-level system dynamics model for the water management in Las Vegas, Nevada. Some issues such as stakeholder interest in the structure of the system, engage participant interest more deeply, and build stakeholder understanding of the basis for management decisions were discussed and analyzed in this study. Tidwell et al. [14] applied SD method to developed water resources management of plants in Middle Rio Grande basin, northcentral New Mexico. They develop a model using Powersim, Inc. to quantitative water conservation strategies in terms of water savings and cost, help public understanding the complexity of the regional water system, and engaging the public in the decision process. They proposed preferred alternative as a result of various runs of the model to balance supply with demand. Ahmadi [15] developed a SD model in order to present an optimum exploitation management plant for Shahr-Chai dam and aquifer water resources at Orumieh province. Ashuri [16] evaluated the probable impacts of transport of water from Qatur-Chai. Bagheri et al. [17] designed a SD modeling to evaluate the urban water system of Bam city during the post disaster situation of Bam earthquake [18]. SD methodology was applied by Hassanzadeh et al. 
[19] for identifying the main factors which declines the level of water in Lake Urmia. In order to determine the best economic choice, Tehrani et al. [20] used dynamic simulation software to model Rasht water well rehabilitation. Chen and Wei [21] applied SD modeling to water security research, and concluded that it can properly solve the complicated relations in a water security system, but exhibits limitations on some issues including research on large systems, influence of social environment changes, uncertainties in water security, and the methods, means, and influence of natural environment changes on water security. An integrated SD simulation model was developed by Kotir et al. [22] to study the feedback processes and interaction between the population, the water resources, and the agricultural production subsectors of the Volta River Basin in West Africa. Their results indicated that the simulated outputs approved by the observed reality of the water resources system. Sahin et al. [23] developed a SD model to simulate suggested changes to water governance through the integration of supply, demand and asset management processes. The developed model can reorganize to cope with systemic change and uncertainty. Gohari et al. [24] used a SD model to examine adaptation strategies taking into account feedbacks between water resources development and biophysical and socioeconomic subsystems. Chhipi-Shrestha et al. [25] proposed a comprehensive water-energy-carbon nexus model for an urban water system using SD approach to assist municipalities, urban developers, and policy makers for neighborhood water planning and management.

By considering the above successful application of SD modeling, the aims of the present study is to develop a simulation model using the system dynamics to improve the better understanding of the Tabriz plain water resources, its dynamics, determine the amount of supply and deficits in municipal-industrial and agricultural uses and the safe level of the water table. To reach integrated water resources management, the use of both surface and groundwater resources were considered in the model. To access this goal, sustainable removal rates of the aquifer have been evaluated with respect to the present water level position through defining the limit of the fluctuations in the groundwater levels. Then, various alternatives including the development of sewage collection networks, enhancement of agricultural efficiency, climate changes effects, artificial recharge and changes of the allocation of the surface and groundwater resources in supplying water needs and also the combination of these strategies have been investigated to determine the aquifer storage fluctuation..

\section{Description of the Study Area}

Tabriz plain in the northwest of Iran located in Central Iran Structural Zone [26]. This plain with area of 870 square kilometers is a part of the Tabriz watershed $(5482 \mathrm{Km} 2)$ as illustrated in Figure 2. Ajichai River is the largest permanent river in the Tabriz plain that enters to the plain from north-eastern part. Other rivers that enters to the Tabriz plain with hydrometric stations data are Anakhatun, Pardil, Haravi and Zinchabchai. Tabriz plain located in the realm of semiarid climate regions [26] with yearly average temperature and humidity of $12.50 \mathrm{C}$ and $53.7 \%$, respectively. Long-term mean annual precipitation (period of 54 years) of the study area is about $290 \mathrm{~mm}$ [27]. The region has a population of approximately 1,489,000 people. Tabriz plain bounded by Sahand Mountains (eastern side), Muro and Misho Mountains (north and west side), and Orumieh Lake moor lands (south and south-west side). Formation of Tabriz plain is due to sedimentation of river deposits in which the most important of them is Ajichai river that entered to the plain from north and rivers that originated from Sahand Mountains in the eastern parts of the plain. Lake deposits from Orumieh lake as impermeable layers are found in some parts of Tabriz plain, spatially in southern parts which ended to salt marsh lands near Orumieh Lake (see Figure 3). Since 1961, more than 44 exploration well have been bored to investigate Tabriz plain aquifer. According to the logs of the exploration wells, Tabriz plain bedrock is composes of Miocene marls and due to lake deposits in some parts of the plain, the aquifer behave as a confined aquifer. Main part of Tabriz aquifer is composed of fine sand and silt. 2146 water well and 310 Qanats were drilled in the aquifer, and most of which concentrated in a strip along eastern border. Agriculture usages with a consumption of about $113 \times 106 \mathrm{~m} 3$ is the biggest consumer of the water resources of Tabriz plain. Since 1963, 136 observation well have been bored and equipped to record water table elevation in monthly basis. Aquifer hydrodynamic parameters have been determined for Tabriz plain aquifer using pumping tests performed in a 145 water wells.

\section{Methodology}

A conceptual model of the Tabriz plain surface water and groundwater resources initially got prepared and then water balance parameters were calculated. The next step was developing a comprehensive system dynamics model using mentioned information in the previous section. Finally, safety water table elevation and different scenarios and policies were performed and evaluated on the system dynamics model after model calibration and validation.

At first step using all of the inflow and outflow components to the Tabriz plain a conceptual model was built. Before starting the model development, it was necessary to collect and analyze geology [28], hydrogeology [27], hydrology [29], meteorology [29], agriculture [30], water resources and uses [31] of the study area.

A water balance of the study area get prepared from the water table elevation in piezometers, the discharge of pumping wells, Qanats and hydrometric stations [27], information of the meteorological stations such as the temperature, 
precipitation and evaporation [32] and data of the population. Water balance calculations of the study area can be expressed as:

$\left(U_{\text {in }}+S_{\text {in }}+R_{r}+R_{i}+P_{i}+A g_{s r}+A g_{u r}+D O_{r}+R_{r}\right)-\left(U_{\text {out }}+E T+A g_{s}+A g_{u}+D o+R_{c}+Q_{w},\right)=\Delta S$

Where $U_{\text {in }}$ is the subsurface inflow from adjacent aquifer(s), $S_{\text {in }}$ the surface recharge from runoff, $R_{i}$ the groundwater recharge by the river, $P_{i}$ the aquifer recharge from precipitation, $A g_{s r}$ the irrigation return flow for agricultural uses supplied by river, $\mathrm{Ag}_{\mathrm{ur}}$ the irrigation return flow for agricultural uses supplied by aquifer, $\mathrm{DO}_{\mathrm{r}}$ the return flow from municipal-industrial uses, $R_{r}$ the surface recharge from river (s), $U_{\text {out }}$ the subsurface outflow, ET the groundwater evaporation, $\mathrm{Ag}_{\mathrm{s}}$ the exploited river water used in agriculture sector, $\mathrm{Ag}_{\mathrm{u}}$ the exploited groundwater used in agriculture sector, Do the municipal-industrial uses, $\mathrm{R}_{\mathrm{c}}$ the groundwater drainage by the river (s), $\mathrm{Q}_{\mathrm{q}}$ the groundwater discharge by Qanats. The $\Delta \mathrm{S}$ is the aquifer storage change during a specific period (monthly).

Subsurface water inflow-outflow ( $U_{\text {in }}$ and $U_{\text {out }}$ ) and groundwater drainage-recharge from Ajichai and other four rivers $\left(R_{r}\right.$ and $\left.R_{c}\right)$ were calculated using Darcy's law after preparing the isopotential maps with monthly time step during the modeling period. Irrigation return water for agricultural uses supplied by aquifer and river $\left(\mathrm{Ag}_{\mathrm{ur}}\right.$ and $\left.\mathrm{Ag}_{\mathrm{sr}}\right)$ calculated using cropping pattern and agricultural efficiency. Return water from municipal-industrial uses $\left(\mathrm{DO}_{\mathrm{r}}\right)$ estimated by aid of unsaturated media data of the exploration wells.

Data of discharge from the wells $\left(\mathrm{Ag}_{\mathrm{s}}+\mathrm{Ag}_{\mathrm{u}}\right)$ and qanats $\left(\mathrm{Q}_{\mathrm{w}}\right)$, the consumption of municipal, agriculture and industry (Do) were collected from available data and analysed for a six-year period of the modeling. The rate of the evaporation from the aquifer (ET) was calculated from Thornthwaite method after preparing the isodepth maps (and calculating the areas in which depth of water table below five meters to the surface) with monthly time steps. Infiltration from precipitation and surface runoff $\left(\mathrm{R}_{\mathrm{i}}\right.$ and $\left.\mathrm{P}_{\mathrm{i}}\right)$ into the aquifer were estimated using available relationships.

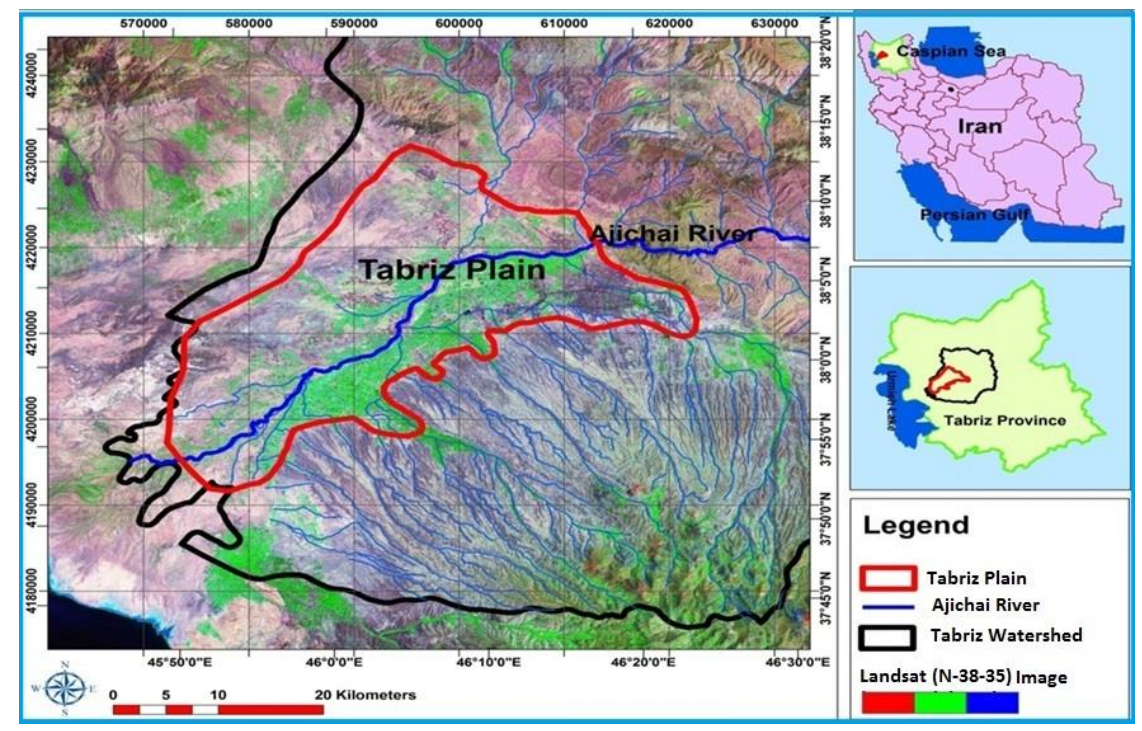

Figure 2. Illustration of the location of the study area

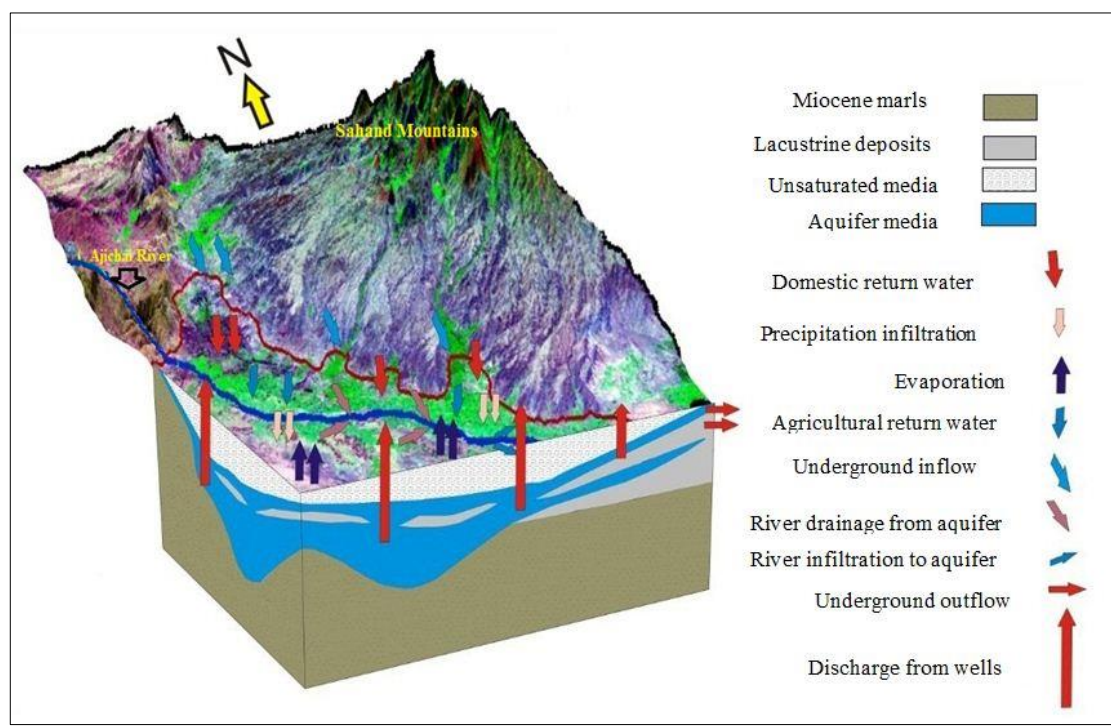

Figure 3. Typical block diagram type conceptual model of Tabriz plain water resources 


\section{Model Developments}

Although some efficient SD modeling packages such as VENSIM (www.vensim.com), STELLA (www.iseesystems.com), SIMILE [34], POWERSIM (www.powersim.com) and SIMULINK — an add-on to MATLAB (www.mathworks.com) are available, in the present study, as a robust tool, VENSIM PLE+ package [34] has been adopted. Vensim's is an industrial strength simulation software to improve the performance of real systems. Its rich feature set emphasizes model quality, connections to data, flexible distribution, and advanced algorithms. More explanations can be find in www.vensim.com. For the describing of SD modeling some elements including interlinked compartments (i.e. stocks), flows (i.e. directed links) and converters (i.e. influences) can be used [35]. While the first element denotes an element where a material is collected (e.g. water in a reservoir), the second one depicts the physical movement of the material into or out of a stock (e.g. river inflow), and the latter one performs to modify the rate of the flows according to some prescribed rules (e.g. evaporation rate), and create feedback within a system along with connecting arrows (i.e. links).

The main steps of the process in the development of Tabriz system dynamics simulation model were as follows: 1) understanding the system and its boundaries by preparing a conceptual model, 2) dividing of the system into system sectors in which each sector described a casual loop diagram by definition of key variables, 3) preparing the structure of the model by converting casual loop diagrams of sectors into a system dynamics model with data and mathematical relations between variables, 4) check the system dynamics model and, 5) the use of the system dynamics model to understand the system behavior and implementation of policies and scenarios.

Based on water balance data and information, a conceptual model representing the study area was build and analyzed, which presented in Figure 3. The next step was to develop a model using monthly time series for inflow and outflow components of the groundwater as well as surface water resources with respect to their correct relationships. To improve our conceptual system understanding, causal diagrams were drawn to show the relationship between these variables and feedback processes as it was illustrated in Figure 4. Then, the variables and specifics of the flow were defined for each of these components according to their application and characteristics stock. Finally, the model was run to analyze the behavior of Tabriz water resources.

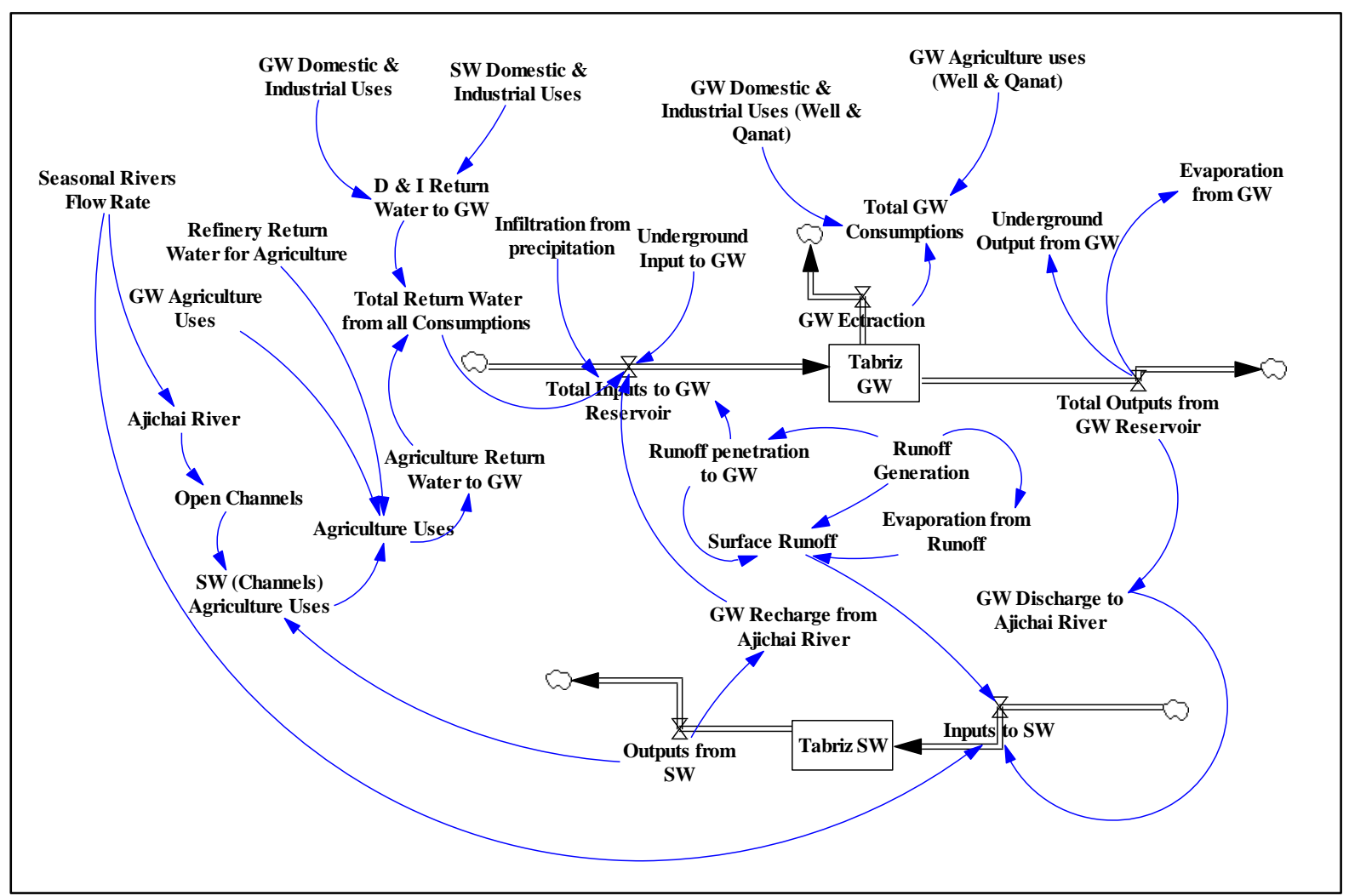

Figure 4. Stock and flow diagram of Tabriz plain water resources. Note: SW: surface water, GW: groundwater

\section{Results and Discussion}

The hydraulic and hydrodynamic characteristics of the aquifer were analysed based on the observed values with respect to the discharge and recharge parameters. The calibration of the model is based on monthly time series of the aquifer water level curve. The simulation results together with the observed values are listed in the form of simulation and historical volumetric aquifer average curves in Table 1. It can be concluded that the simulation results of the model generally have a good agreement with the observed values. In order to evaluate the difference between calculated and observed values, statistical parameters including mean error (ME), mean absolute error (MAE), mean absolute 
percentage error (MAPE) and root mean square error (RMSE) were calculated. The results indicated that the percentage error between the calculated data and the historical data was around $\pm 1 \%$. Briefly, it can be said that the model is sufficiently accurate to simulate the behavior of the aquifer by considering the results of the calibration step. Results of the system dynamics simulation of the aquifer storage, groundwater level and parameters for municipal, industrial and agricultural water resources under the present management strategy and environmental conditions (Alt. 0 denotes current conditions) are also represented in Table 1. (see also Figure a. ). The average of groundwater storage in the aquifer during the modeling period is about 2500 million cubic meters (MCM), and the safe exploitation amount of water is about 152 MCM per year. Municipal demand is about 104 MCM per year from which about 95 MCM supplied from outside of the Tabriz plain (inter-basin flow) and about 9 MCM remnants supplied from groundwater reservoir. Per capita consumption of drinking water capita per day is 0.19 cubic meters and population of the study area is about $1,489,000$ people. Crop cultivation is 13,200 hectares. Water required per hectare averaged annually is 3,868 cubic meters. Agricultural efficiency in Tabriz plain is low and about 34 percent. Agricultural demand averaged annually is about $150 \mathrm{MCM}$, from which 61.5 MCM was supplied from surface water and waste water and 54 MCM supplied from groundwater. Therefore, an average 34.5 MCM of water shortage is in agriculture activities. The model shows an agricultural demand deficiency occurred 18 months during the 72 months period of modeling, so in $25 \%$ of cases there is a shortage of the water for the agricultural needs.

Table 1. Results of the simulation of Tabriz plain water resources and parameters of aquifer, uses (municipal-industry and agriculture) and deficits under different operating management policies.

\begin{tabular}{|c|c|c|c|c|c|c|}
\hline \multirow[t]{2}{*}{ Parameters } & \multicolumn{6}{|c|}{ Results of the scenarios } \\
\hline & Alt. 0 (Current) & Alt. 1 & Alt. 2 & Alt. 3 & Alt. 4 & Alt. 5 \\
\hline Time (Month) & 72 & 72 & 72 & 72 & 72 & 72 \\
\hline \multicolumn{7}{|l|}{ Aquifer } \\
\hline Yearly average of groundwater volume (MCM) & 2503 & 2,513 & 2459 & 2474 & 2500 & 2481 \\
\hline Final groundwater volume (MCM) & 2506 & 2,532 & 2419 & 2454 & 2507 & 2470 \\
\hline Yearly average of available groundwater (Supply) (MCM) & 150.8 & 132.72 & 100.4 & 94.28 & 103.16 & 96.92 \\
\hline Yearly average of well and Qanats extraction (MCM) & 149.8 & 149.8 & 149.8 & 149.8 & 149.8 & 149.8 \\
\hline Yearly average of groundwater storage variation (MCM) & 0.99 & 5.39 & -13.45 & -7.58 & 1.29 & -4.94 \\
\hline \multicolumn{7}{|l|}{ Municipal and industrial parameters } \\
\hline Yearly average of domestic and industrial demand (MCM) & 103.78 & 103.78 & 103.78 & 103.78 & 103.78 & 103.78 \\
\hline Yearly average of surface water domestic and industrial supply (MCM) & 95.05 & 95.05 & 95.05 & 95.05 & 95.05 & 95.05 \\
\hline Yearly average of surface water out deficit (MCM) & 8.72 & 8.72 & 8.72 & 8.72 & 8.72 & 8.72 \\
\hline Yearly average of groundwater domestic and industrial supply (MCM) & 8.72 & 8.72 & 8.69 & 8.63 & 8.72 & 8.72 \\
\hline Yearly average of total domestic and industrial deficit (MCM) & 0.00 & 0.00 & 0.30 & 0.09 & 0.00 & 0.00 \\
\hline Yearly average of population in model domain (M) & 1.49 & 1.49 & 1.49 & 1.49 & 1.49 & 1.49 \\
\hline Yearly average of consumption (per capita/day) (m3) & 0.19 & 0.19 & 0.19 & 0.19 & 0.19 & 0.19 \\
\hline Number of months of municipal-industry supply with deficit of $10-20 \%$ & 0.00 & 0.00 & 0.00 & 0.00 & 0.00 & 0.00 \\
\hline Number of months of municipal -industry supply with deficit of $20-30 \%$ & 0.00 & 0.00 & 0.00 & 0.00 & 0.00 & 0.00 \\
\hline Number of months of municipal -industry supply with deficit of $30-50 \%$ & 0.00 & 0.00 & 0.00 & 0.00 & 0.00 & 0.00 \\
\hline Number of months of municipal -industry supply with deficit of $>50 \%$ & 0.00 & 0.00 & 0.00 & 0.00 & 0.00 & 0.00 \\
\hline \multicolumn{7}{|l|}{ Agricultural Parameters } \\
\hline Yearly average of agricultural demand (MCM) & 150.19 & 127.66 & 113.47 & 102.12 & 102.12 & 102.12 \\
\hline $\begin{array}{l}\text { Yearly average of surface water and refinery of agricultural supply } \\
\text { (MCM) }\end{array}$ & 61.41 & 63.9 & 64.83 & 61.80 & 61.80 & 61.80 \\
\hline Yearly average of surface water agricultural deficit (MCM) & 88.77 & 63.75 & 48.64 & 40.32 & 40.32 & 40.32 \\
\hline Yearly average of groundwater agricultural supply (MCM) & 54.29 & 37.01 & 21.81 & 18.38 & 20.54 & 20.01 \\
\hline Yearly average of total agricultural deficit (MCM) & 34.47 & 26.74 & 26.82 & 21.94 & 19.78 & 20.30 \\
\hline Yearly average net irrigation requirement ( $\left.\mathrm{m}^{3} / \mathrm{ha}\right)$ & 3,868 & 3,868 & 3,868 & 3,868 & 3,868 & 3,868 \\
\hline Agricultural area (ha) & 13,200 & 13,200 & 13,200 & 13,200 & 13,200 & 13,200 \\
\hline Agricultural efficiency & 0.34 & 0.4 & 0.4 & 0.5 & 0.5 & 0.5 \\
\hline Number of months of agricultural supply with deficit of $10-20 \%$ & 3 & 3 & 1 & 3 & 2 & 1 \\
\hline Number of months of agricultural supply with deficit of $20-30 \%$ & 3 & 3 & 3 & 2 & 3 & 3 \\
\hline Number of months of agricultural supply with deficit of $30-50 \%$ & 5 & 5 & 7 & 6 & 6 & 7 \\
\hline Number of months of agricultural supply with deficit of $>50 \%$ & 7 & 6 & 7 & 7 & 5 & 5 \\
\hline
\end{tabular}




\subsection{Safe Groundwater Level and Storage of the Aquifer}

The aquifer water level drops during the dry period and recovers during the wet period. The optimal groundwater fluctuations is met when the groundwater is extracted in such way that annual exploitation equals to the annual renewable water. Therefore, the aquifer water level fluctuates within an area where it's upper and lower boundaries are coincided to the water level in wet and dry periods, respectively. The aquifer groundwater level should not be so high that land could become rheumy and unusable or so low that the aquifer cannot make up for the loss in the wet periods. In other words, the exploitation of groundwater resources should be in a way that the reproducible water of the aquifer has been used and do not suffer a permanent loss in the aquifer. This limit is equal to the amount of the renewable water. Additionally, the groundwater level should be high enough that land drainage system would be required. This limit with respect to the type and texture of the unsaturated media sediments of the plain is about two meters below ground surface. It should be noted that this value is not fixed and depends on soil type and texture in different regions varies across the aquifer. Two values (i.e. the maximum and minimum safe levels of the water table) for safe limits of groundwater level fluctuations were introduced to the model. Due to these restrictions, the safe exploitation from the aquifer was calculated with monthly time steps as illustrated in Figure 5. Current average of the aquifer groundwater level is $1318.65 \mathrm{~m}$ above mean sea level (MSL). Average of minimum safe level of the aquifer water table in the modeling period is $1317.35 \mathrm{~m}$ above MSL. The results indicated that groundwater levels are deeper than the minimal level, and thus there are fewer problems for the first limit (i.e. the maximum safe level), than the second one (i.e. the minimum safe level).

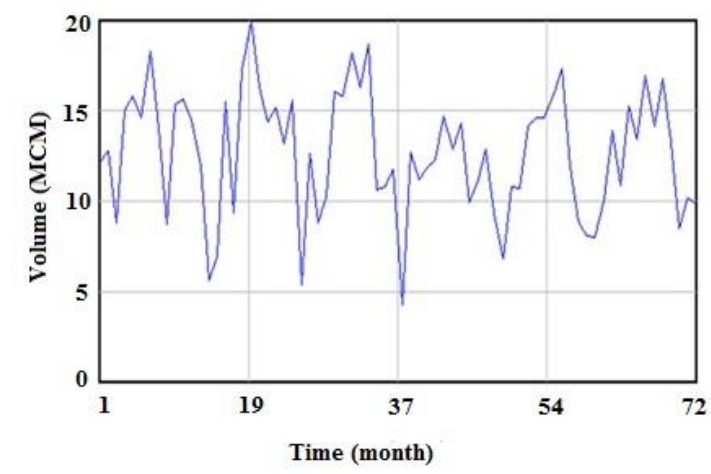

Figure 5. Safe amount of the exploitation in the modeling period

By considering Table 2, the monthly and annually of the average volume of the water allowed to be exploited during the modeling period respectively are about 13 and $152 \mathrm{MCM}$. The average of maximum safe level of water table is 1322.34 m above MSL. Maximum safe rise of the groundwater level from the averaged current groundwater level varies from 1.90 to $5.06 \mathrm{~m}$ in the different months and average of change during the six-year of the modeling is $3.69 \mathrm{~m}$. The maximum drawdown of the aquifer groundwater level from the average current groundwater level varies from 0.06 to $2.31 \mathrm{~m}$ and the average change is $1.30 \mathrm{~m}$ in different months (see Table 2). The maximum volume of water that could be stored in the aquifer without any restriction varies from at least 32.69 up to $87.91 \mathrm{MCM}$ per month and the monthly and annually averages of it during modeling period respectively are 64.09 and 769.12 MCM.

Table 2. Groundwater level and safe exploited groundwater from the aquifer in the modeling period (the order of months is according to a water year of the study area)

\begin{tabular}{cccccccc}
\hline $\begin{array}{c}\text { Time } \\
\text { (month) }\end{array}$ & $\begin{array}{c}\text { Maximum safe } \\
\text { exploited water } \\
\text { from the aquifer } \\
\text { (MCM/Year) }\end{array}$ & $\begin{array}{c}\text { Minimum } \\
\text { water table } \\
\text { level }(\mathbf{m})\end{array}$ & $\begin{array}{c}\text { Current } \\
\text { groundwater level } \\
\mathbf{( m )}\end{array}$ & $\begin{array}{c}\text { Maximum } \\
\text { water table } \\
\text { level (m) }\end{array}$ & $\begin{array}{c}\text { Maximum safe } \\
\text { rising of } \\
\text { groundwater } \\
\text { level (m) }\end{array}$ & $\begin{array}{c}\text { Maximum safe } \\
\text { lowering of } \\
\text { groundwater } \\
\text { level (m) }\end{array}$ & $\begin{array}{c}\text { Maximum } \\
\text { capacity of } \\
\text { aquifer for water } \\
\text { storage (MCM) }\end{array}$ \\
\hline October & 10.40 & 1316.77 & 1317.64 & 1322.34 & 4.70 & 0.87 & 81.69 \\
November & 10.44 & 1315.97 & 1317.28 & 1322.34 & 5.06 & 1.31 & 87.91 \\
December & 11.58 & 1315.71 & 1317.37 & 1322.34 & 4.97 & 1.66 & 86.35 \\
January & 13.66 & 1315.75 & 1317.77 & 1322.34 & 4.57 & 2.02 & 79.48 \\
February & 13.60 & 1316.32 & 1318.40 & 1322.34 & 3.94 & 2.08 & 68.48 \\
March & 15.65 & 1316.71 & 1319.01 & 1322.34 & 3.33 & 2.31 & 57.88 \\
April & 16.58 & 1317.56 & 1319.75 & 1322.34 & 2.59 & 2.19 & 45.04 \\
May & 15.83 & 1318.56 & 1320.31 & 1322.34 & 2.03 & 1.75 & 35.31 \\
June & 12.80 & 1319.59 & 1320.44 & 1322.34 & 1.90 & 0.86 & 32.96 \\
August & 10.61 & 1319.25 & 1319.31 & 1322.34 & 3.03 & 0.06 & 52.69 \\
July & 10.79 & 1318.48 & 1318.67 & 1322.34 & 3.67 & 0.19 & 63.73 \\
September & 10.51 & 1317.58 & 1317.88 & 1322.34 & 4.46 & 0.30 & 77.60 \\
Average & 12.70 & 1317.35 & 1318.65 & 1322.34 & 3.69 & 1.30 & 64.09 \\
\hline
\end{tabular}




\subsection{Design and Evaluation of Policies and Scenarios}

The effect of the different management policies and scenarios of Tabriz plain water resources can be evaluated using the developed system dynamics model. Such model can be also used to evaluate sensitivity of the aquifer storage behaviour to the removal, sudden change and increasing or decreasing of some variables. To reach these goals, a combination of different alternatives were applied on the system dynamics model of Tabriz plain and the results of their implementation in the groundwater level and storage fluctuations have been investigated. These alternatives have been considered two general perspectives including no change in rainfall and reducing rainfall for taking to account the climate changes. Different parameters including the irrigation efficiency, sewage network and changes of the allocation of the surface water were considered in these scenarios. With these regards, five different alternatives were designed as follows:

Alternative 1: $6 \%$ increasing of the agricultural efficiency, $15 \%$ increasing of the refinery capacity (i.e. development of wastewater collection networks) and $2 \mathrm{~m}^{3} / \mathrm{s}$ increasing of the allocation of the surface water (i.e. river and streams) to the irrigation system capacity (see Table 1, Figure b. App. . in Appendix).

Alternative 2: $16 \%$ increasing of the agricultural efficiency, $40 \%$ increasing of the refinery capacity (i.e. sewage network developing) and $2 \mathrm{~m}^{3} / \mathrm{s}$ increasing of the allocation of the surface water (i.e. river and streams) to the irrigation system capacity (see Table 1, Figure c. . in Appendix).

Alternative 3: $16 \%$ increasing of the agricultural efficiency, $45 \%$ increasing refinery capacity (i.e. development of wastewater collection networks) and $2 \mathrm{~m}^{3} / \mathrm{s}$ increasing of the allocation of the surface water (i.e. river and streams) to the irrigation system capacity (see Table 1, Figure d. . in Appendix).

Alternative 4: $16 \%$ increasing of agricultural efficiency, increasing the allocation of the surface water irrigation system capacity by the amount of $2 \mathrm{~m}^{3} / \mathrm{s}, 45 \%$ increasing of the refinery capacity (i.e. sewage network) and feeding the aquifer by the artificial recharge (see Table 1, Figure e. . in Appendix).

Alternative 5: $16 \%$ increasing of the agricultural efficiency, increasing the allocation of the surface water irrigation system capacity by the amount of $2 \mathrm{~m}^{3} / \mathrm{s}, 45 \%$ increase of the refinery capacity (sewage network), feeding the aquifer by artificial recharge and 50\% decreasing of the current precipitation (see Table 1, Figure f. . in Appendix).

The simulation results of five alternatives were summarized in Table 1. As indicated in Table 1, with the alternative in the first case, groundwater storage increases about 5.5 MCM per year. The aquifer storage volume at the end of the modeling is $2532 \mathrm{MCM}$ in this alternative. Groundwater levels also increase progressively in the beginning, but it still remains almost constant and changes in safe limit. Water shortages for agriculture uses in the comparison to the current condition reduces to about $27 \mathrm{MCM}$ and the total percentage of the water shortages for the agriculture to be reduced about $24 \%$ in six years of the modeling period.

By performing the second alternative, the aquifer storage relative to safe limit, reduces about 13.5 MCM. In these conditions, the average volume of the aquifer storage well is about $2459 \mathrm{MCM}$. Groundwater level will have a strong downtrend and in the firth 24 months of the modeling period reduces to below of the safe lower limit of the groundwater level fluctuations. Also, the deficit of the agricultural needs will decrease as indicated in Table 1.

For the third alternative, the aquifer storage bears a shortage of 7.5 MCM from safe limit, and it is $2454 \mathrm{MCM}$ at the end of the simulation period. Groundwater levels fluctuation varies in safe limits from beginning to end during of the first three years of the simulation but then drawdown will increase and stand below to the lower safe limit. Agriculture needs subject to this alternative is about 113.5 MCM per year and the percentage of the water shortages for agriculture is $25 \%$ per year in the modeling period (see Table 1 ).

In the fourth alternative, the aquifer storage volume is $2500 \mathrm{MCM}$ (see Table 1). However, the shortage of the aquifer storage is still about 1.5 MCM. Also, by implementing this alternative, the agricultural needs reduce to about $102 \mathrm{MCM}$ per year and deficit will be about $20 \mathrm{MCM}$. The deficit of the agricultural water supply decreases to about $22.2 \%$ per year in the modeling period.

In order to evaluate the effect of the reducing of the precipitation (i.e. drought) on changes of the aquifer storage, $50 \%$ reduction of the rainfall imposed to the model (i.e. fifth alternative) and the model was run under these conditions. The simulation results are also represented in Table 1 . In this alternative, the average aquifer storage volume is 2481 MCM and at the end of modeling period come to $2470 \mathrm{MCM}$. The maximum amount of water allowed to be extracted under these conditions is about $93 \mathrm{MCM}$ per year and the aquifer storage volume is about $5 \mathrm{MCM}$. The agricultural needs are similar to the previous alternative, but will change in the amount of the shortage.

Applying various operation alternatives shows that increasing of the cultivation with respect to the current condition of agricultural efficiency in Tabriz plain is not operational. Thus, in order to protecting the water resources agricultural efficiency must be increased.

Planning on surface water resources in allocation have great uncertainty and cannot be reliable with respect to intensive changes in river discharge. Developing of the sewage collection networks is necessary due to its importance in irrigation and avoiding problems related to the sewage. In accordance of drought due to high vulnerability of the 
water resources of the plain to the precipitation, groundwater level and storage will be reduced and as a result in drought periods it is necessary to planning of decreasing in water extraction from the aquifer.

\section{Conclusion}

Among some available models, system dynamics provides a simulation tool to model feedback relations in a system. Because the Tabriz plain has a complicated structure, the use of SD modeling for this can demonstrate the robustness of it.

During the six years of the modeling period, the monthly and annually averaged of maximum exploitation of the aquifer without limitation in the withdrawal groundwater level respectively are about 13 and $152 \mathrm{MCM}$. The minimum and maximum levels of the averaged water table of the aquifer are 1317.35 and $1322.35 \mathrm{~m}$, respectively.

As shown in this research, the system dynamic modeling approach aids the planner to evaluate system performance for each objective and to explore the impact of changes in the management policies. The alternative of the increasing the efficiency of agriculture, the development of the sewage collection networks and the increasing the allocation of the surface water caused increase, decrease and increase of the aquifer storage respectively; in which the effect of the development of the sewage collection networks in the aquifer storage fluctuations is greater with respect to its significant amount. Due to the severe fluctuations of the river discharge, enhance of the allocation of the surface water to the agricultural uses does not have severe changes in the groundwater level and storage. By increasing of $45 \%$ of the refinery capacity (i.e. development sewage network) relative to the current condition, in order to avoid the aquifer storage reductions, the surface water allocation should be $2 \mathrm{~m} 3 / \mathrm{s}$ and $16 \%$ increases of agricultural efficiency and also the implementation of artificial recharge should be considered. By the occurrence of drought (i.e. rainfall reducing by more than 50\% relative to current conditions), the policy of increasing the agricultural efficiency and the allocation of the surface water, respectively, by $16 \%$ and $2 \mathrm{~m} 3 / \mathrm{s}$, will not be able to prevent a reduction in the aquifer storage and the water level drawdown. Consequently, in this conditions it could be suggested that the efficiency of the irrigation should be increased. The implementation of different management alternatives on Tabriz plain water resources in the current operation and management policy showed that the groundwater supply have been extremely reduced when the drought occurs.

\section{References}

[1] Akbari, Gholam H., and Reza Barati. "Comprehensive analysis of flooding in unmanaged catchments." In Proceedings of the Institution of Civil Engineers-Water Management, vol. 165, no. 4, pp. 229-238. Thomas Telford Ltd, 2012.

[2] Akbari, Gholam H., Alireza H. Nezhad, and Reza Barati. "Developing a model for analysis of uncertainties in prediction of floods." Journal of Advanced Research 3, no. 1 (2012): 73-79.

[3] Barati, Reza, Sajjad Rahimi, and Gholam Hossein Akbari. "Analysis of dynamic wave model for flood routing in natural rivers." Water Science and Engineering 5, no. 3 (2012): 243-258.

[4] Barat, Reza, Gholam Hossein Akbari, and Sajjad Rahimi. "Flood Routing of an Unmanaged River Basin Using Muskingum-Cunge Model; Field Application and Numerical Experiments." Caspian Journal of Applied Sciences Research 2, no. 6 (2013).

[5] World water forum (the 3rd) Final Report. 16-23 March, Kyoto, Japan, 2003.

[6] Simonovic PS. Managing water resources, methods and tools for a systems approach. UNESCO Publication, Paris, 2009.

[7] Adinehvand R. System Dynamics Modeling for Integrated Management Groundwater Resources of Tabriz Plain. M.Sc. thesis in hydrogeology, University of Shahid Beheshti, Tehran, Iran, 2012 (in Persian).

[8] Forrester J. W. Urban Dynamics. The MIT Press, Cambridge, Massachusetts, 1969.

[9] I. G. Winz Brierley, S. Throwsdale, The Use of system dynamics simulation in water resources management. Water Resour. Manage, 2009; 23: 1301-1323.

[10] Sterman, John D. John D. Business dynamics: systems thinking and modeling for a complex world. No. HD30. 2 S7835 2000.

[11] Sehlke, Gerald, and Jake Jacobson. "System dynamics modeling of transboundary systems: the Bear River basin model." Groundwater 43, no. 5 (2005): 722-730.

[12] Madani, Kaveh, and Miguel A. Mariño. "System dynamics analysis for managing Iran's Zayandeh-Rud river basin." Water resources management 23, no. 11 (2009): 2163-2187.

[13] Stave A. A System Dynamics Model to Facilitate Public Understanding of Water Management Options in Las Vegas, Nevada. J. Environ. Manage, 2003; 67: 303-313.

[14] Tidwell VD. Passell HD. Conrad SH. Thomas RP. System dynamics modeling for community-based water planning: application to the Middle Rio Grande. J. Aquat. Sci., 2004; 66: 357-372. 
[15] Ahmadi S. Shahr-Chai Water Resources Operational Modeling Using System Dynamics. M.Sc. thesis in hydrogeology, University of Shahid Beheshti, Tehran, Iran, 2009 (in Persian).

[16] Ashuri M. Water Resources Management in Khoy Plain Using System Dynamic Modeling. M.Sc. thesis in hydrogeology, University of Shahid Beheshti, Tehran, Iran, 2010 (in Persian).

[17] Bagheri A. Darijani M. Asgary A. Morid S. Crisis in urban water systems during the reconstruction period: a system dynamics analysis of alternative policies after the 2003 earthquake in Bam-Iran. Water resources management, 2010; 24: 2567-2596.

[18] Ghashghaie M. Bagheri A. Morid S. Rainfall-runoff modeling in a watershed scale using an object oriented approach based on the concepts of system dynamics. Water Resour. Manage., 2013; 27: 5119-5141.

[19] Hassanzadeh E. Zarghami M. Hassanzadeh Y. Determining the main factors in declining the Urmia Lake level by using system dynamics modeling. Water Resour. Manage., 2012; 26: 129-145.

[20] Tehrani MV. Alikhani L. Ameriun MS. Tashayoi HR. Well rehabilitation in Rasht: a system dynamics approach. Proc. Inst. Civ. Eng. Water Manage., 2011; 164: 221-228.

[21] Chen Z. Wei S. “Application of system dynamics to water security research.” Water Resour. Manage., 2014; 28: 287-300.

[22] Kotir JH. Smith C. Brown G. Marshall N. Johnstone R. “A system dynamics simulation model for sustainable water resources management and agricultural development in the Volta River Basin, Ghana." Sci. Total Environ., 2016; 573, 444-457.

[23] Sahin O. Siems RS. Stewart R.A. Porter MG. "Paradigm shift to enhanced water supply planning through augmented grids, scarcity pricing and adaptive factory water: a system dynamics approach." Environ. Modell. Software, 2016; 75, 348-361.

[24] Gohari A. Mirchi A. Madani K. "System Dynamics Evaluation of Climate Change Adaptation Strategies for Water Resources Management in Central Iran.” Water Resour. Manage., 2017; 31(5), 1413-1434.

[25] Chhipi-Shrestha G. Hewage K. Sadiq R. "Water-Energy-Carbon Nexus Modeling for Urban Water Systems: System Dynamics Approach.” J. Water Resour. Plann. Manage., 2017; 143(6), 04017016.

[26] Serteser A. Kargoglu M. Senkul C. Konouk M. “An Assessment on Bioclimatic Requirements of Endomic Quercus aucheri Juab.” Spach. Communities Spreading South-West Anatolia, Turkey. Asian J. Plant Sciences, 2009; 8: 35-41.

[27] East Azarbaijan Water Authority Hydrogeology of Tabriz Plain Report. Tabriz, Iran, Yekom consulting engineering: EARWA, 2009.

[28] Stocklin J. Structural history and Tectonic of Iran, A review American Am. Assoc. Pet. Geol. Bull. American. 1968; 52: 12291258.

[29] East Azarbaijan Regional Water Authority, Hydrology and Meteorology Studies of Tabriz Plain Report. Tabriz, Iran: EARWA, 1996.

[30] East Azarbaijan Regional Water Authority, Agricultural Report of Tabriz Plain. Tabriz, Iran, Yekom consulting engineering: EARWA, 2011a.

[31] East Azarbaijan Regional Water Authority, Water Requirement. Tabriz, Iran, Yekom consulting engineering: EARWA, 2011 b.

[32] Iran Meteorological Organization (IMO) NETWAT Program: A Prepared Program for Agriculture and Irrigation Studies in Different Regions of Iran. Tehran, Iran, 2011.

[33] Muetzelfeldt R. Massheder J. The simile visual modelling environment. Eur. J. Agron., 2003; 18:345-358.

[34] Ventana systems Inc. Ventana Simulation Environment, Vensim; Users Guide. Version 5.5d, 2007.

[35] Sušnik J. Molina JL. Vamvakeridou-Lyroudia LS. Savić DA. Kapelan Z. Comparative analysis of system dynamics and objectoriented Bayesian networks modelling for water systems management. Water Resour. Manage. 2013; 27: 819-841. 


\section{Appendix}

Supplementary materials of the simulations for the present condition and five different scenarios (see also Table 1).

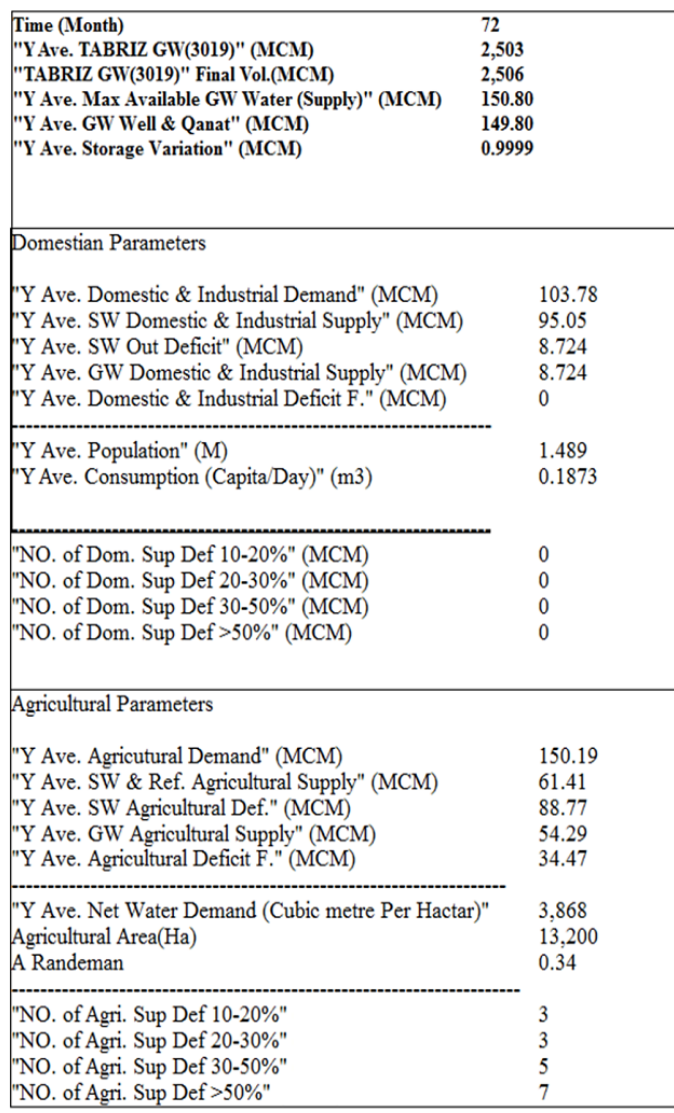
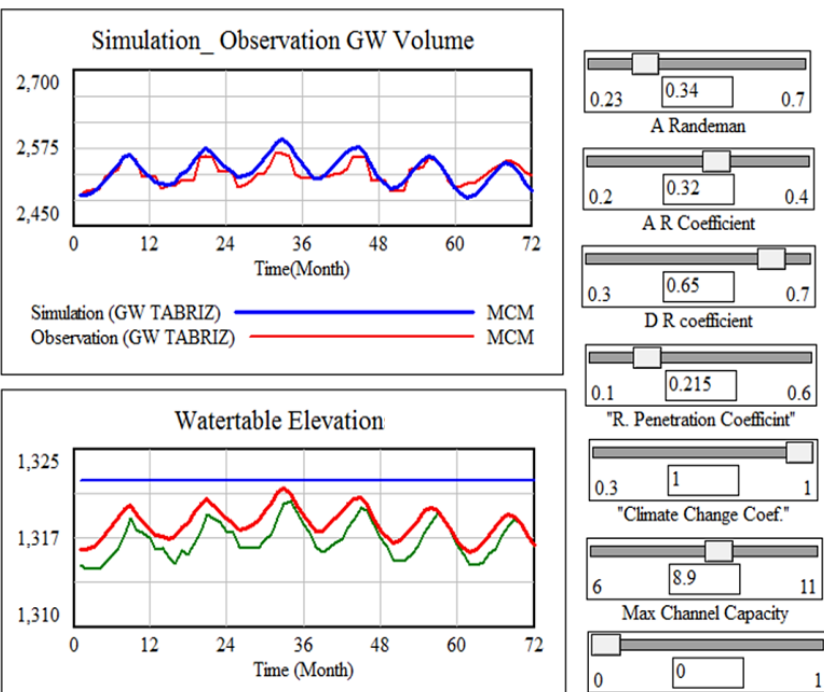

Max WT Elevation WT Elevation
Min WT Elevation m

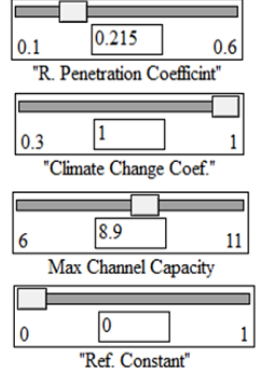

Figure a. Results of the simulation of Tabriz plain water resources and parameters of aquifer, uses (domestic-industry and agriculture) and deficits under the current operating policy. Note: MCM: million cubic meter, GW: groundwater

\begin{tabular}{|c|c|}
\hline $\begin{array}{l}\text { Time (Month) } \\
\text { "Average of Tabriz GW Reservoir Volume" (MCM) } \\
\text { "Tabriz GW Final Volume" (MCM) } \\
\text { "Average of Maximum Available GW (Supply)" (MCM) } \\
\text { "Average of Well \& Qanat Extraction" (MCM) } \\
\text { "Average of Storage Variation" (MCM) }\end{array}$ & $\begin{array}{l}72 \\
2,513 \\
2,532 \\
132.72 \\
149.80 \\
5.390\end{array}$ \\
\hline $\begin{array}{l}\text { Time [Month) } \\
\text { Domestian Parameters }\end{array}$ & 72 \\
\hline $\begin{array}{l}\text { "Average of Domestic } \& \text { Industrial Demand" (MCM) } \\
\text { "Average of Surface water Domestic \& Industrial Supply" (MCM) } \\
\text { "Average of Surface water Deficit" (MCM) } \\
\text { "Average of Groundwater Domestic \& Industrial Supply" (MCM) } \\
\text { 'Average of Domestic \& Industrial Deficit" (MCM) }\end{array}$ & $\begin{array}{l}103.78 \\
95.05 \\
8.724 \\
8.724 \\
0\end{array}$ \\
\hline $\begin{array}{l}\text { "Population" (Million people) } \\
\text { "Average of Consumption [Capita/Day)" (cubic meters) }\end{array}$ & $\begin{array}{l}1.489 \\
0.1873\end{array}$ \\
\hline $\begin{array}{l}\text { "Nomber of Months of Domestic and industrial Supply with Deficit of 10-20\% } \\
\text { "Nomber of Months of Domestic and industrial Supply with Deficit of } 20-30 \% \\
\text { "Nomber of Months of Domestic and industrial Supply with Deficit of } 30-50 \%\end{array}$ & $\begin{array}{ll}\% " & 0 \\
\% " & 0 \\
\% " & 0 \\
& 0\end{array}$ \\
\hline $\begin{array}{l}\text { Time (Month) } \\
\text { Agricultural Parameters }\end{array}$ & 72 \\
\hline $\begin{array}{l}\text { "Average Agricutural Demand" (MCM) } \\
\text { "Average of Surface water \& Refinery Agricultural Supply" (MCM) } \\
\text { "Average Surface Agricultural Deficit" (MCM) } \\
\text { "Average Groundwater Agricultural Supply" (MCM) } \\
\text { "Average Agricultural Deficit" (MCM) }\end{array}$ & $\begin{array}{l}127.66 \\
63.90 \\
63.75 \\
37.01 \\
26.74\end{array}$ \\
\hline $\begin{array}{l}\text { "Average of Net Water Demand" (Cubic metre Per Hectare) } \\
\text { "Agricultural Area" }(\mathrm{Ha}) \\
\text { "Agricultural Efficieney" (Percent) }\end{array}$ & $\begin{array}{l}3,868 \\
13,200 \\
0.4\end{array}$ \\
\hline $\begin{array}{l}\text { "Nomber of Months of Agriculture Supply with Deficit of 10-20\%" } \\
\text { "Nomber of Months of Agriculture Supply with Deficit of 20-30\%" } \\
\text { "Nomber of Months of Agriculture Supply with Deficit of 30-50\%" } \\
\text { "Nomber of Months of Agriculture Supply with Deficit >50\%" }\end{array}$ & $\begin{array}{l}3 \\
3 \\
5 \\
6\end{array}$ \\
\hline
\end{tabular}
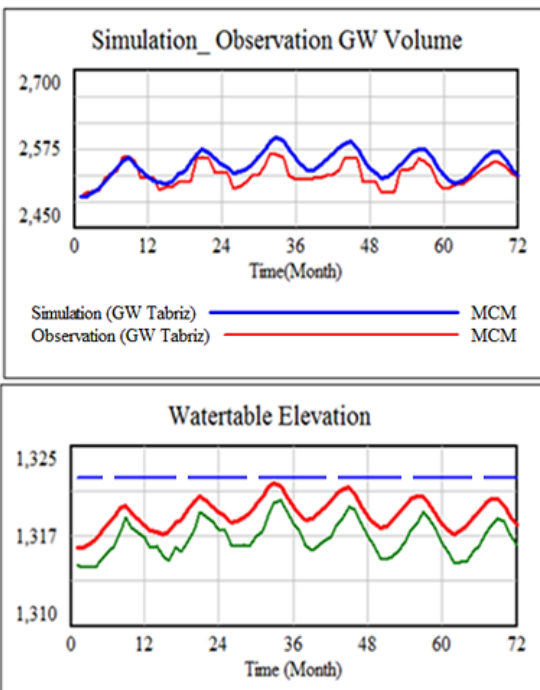

Maximum Allowable Water table Elevation $-\square-\square-\square$
Simulated Water table Elevation Simulated Water table Elevation
Minimum Allowable Water table Elevation

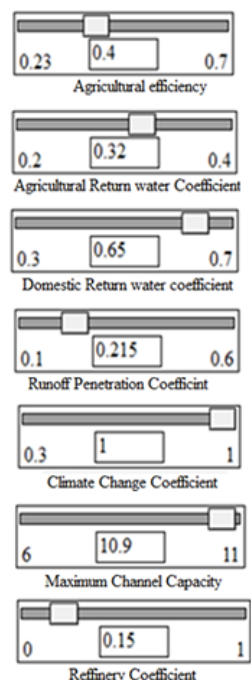

Figure b. App. The simulation results of first scenario: Increasing allocation of surface water (i.e. $2 \mathrm{~m}^{3} / \mathrm{s}$ ) and agricultural efficiency (i.e. 6\%) and sewage collection networks development (i.e. 15\% increasing of the refinery capacity), and their effects on aquifer storage and parameters related to agricultural, domestic and industry consumptions 


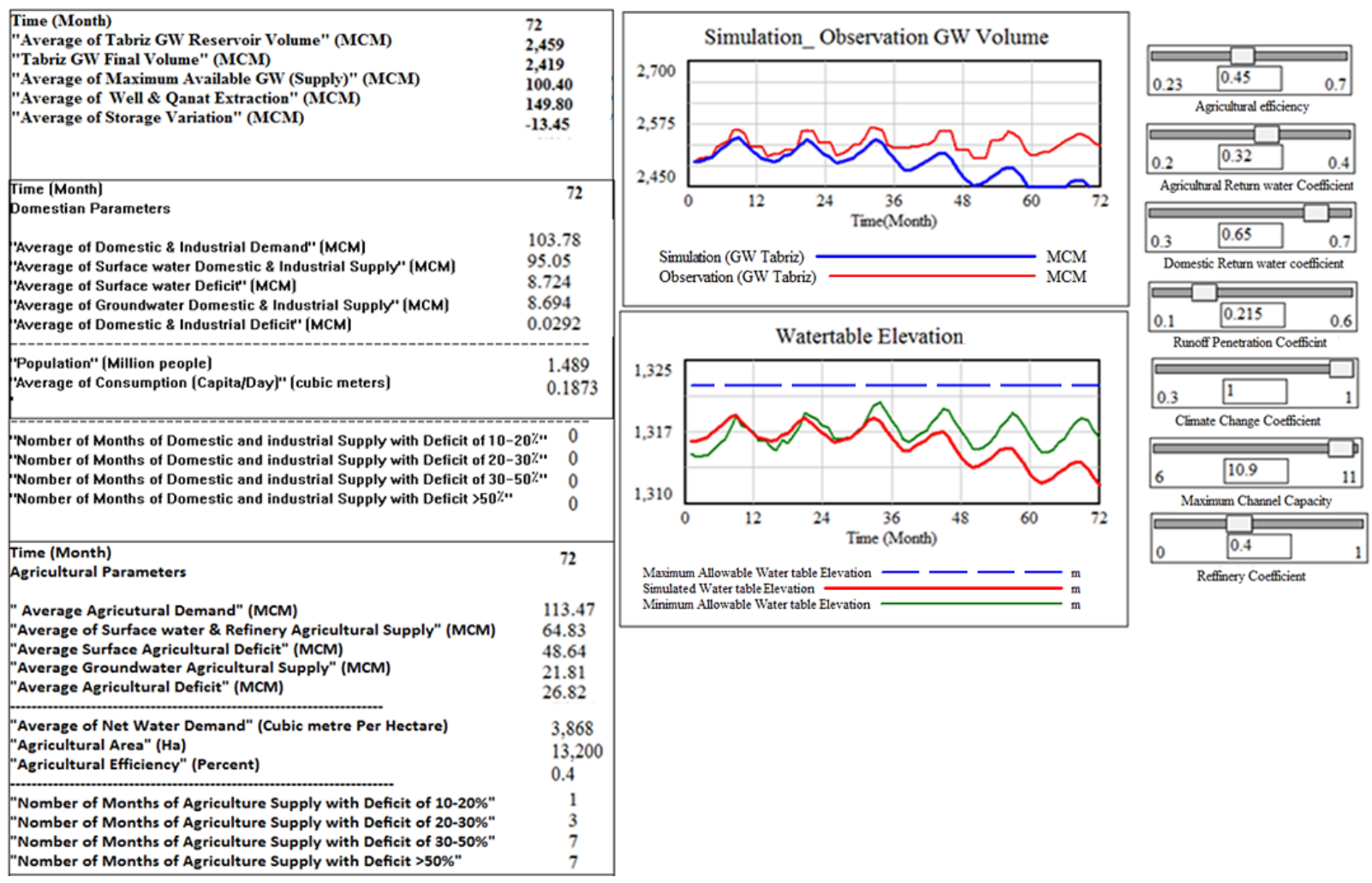

Figure c. The simulation results of second scenario: Increasing allocation of surface water (i.e. $\left.2 \mathrm{~m}^{3} / \mathrm{s}\right)$ and agricultural efficiency (i.e. 16\%) and sewage collection networks development (i.e. $40 \%$ increasing of the refinery capacity), and their effects on aquifer storage and parameters related to agricultural, domestic and industry consumptions.

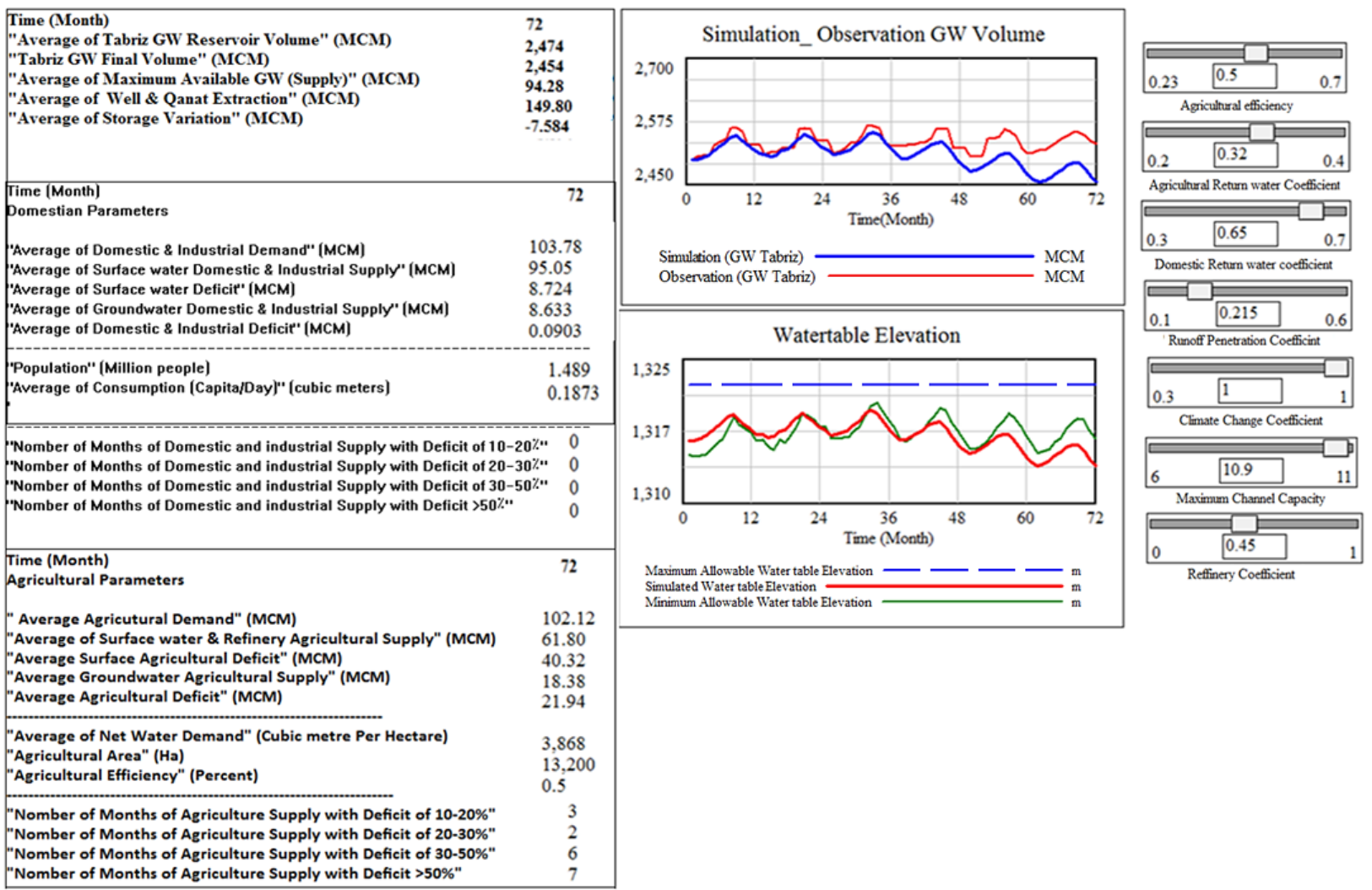

Figure d. The simulation results of third scenario: Increasing allocation of surface water (i.e. $\left.2 \mathrm{~m}^{3} / \mathrm{s}\right)$ and agricultural efficiency (i.e. 16\%) and sewage collection networks development (i.e. $45 \%$ increasing of the refinery capacity), and their effects on aquifer storage and parameters related to agricultural, domestic and industry consumptions. 


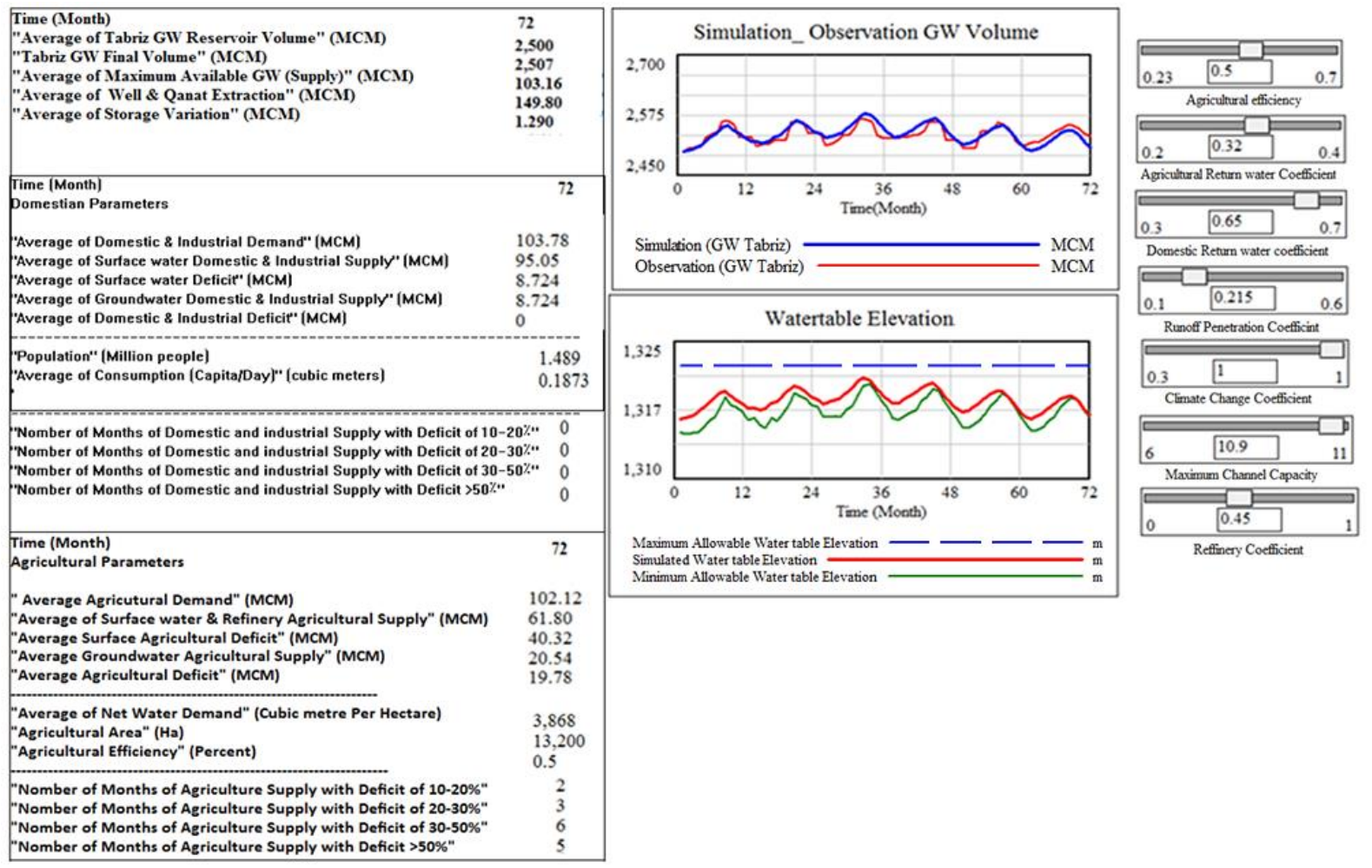

Figure e. The simulation results of fourth scenario: The simulation results of third scenario: Increasing allocation of surface water (i.e. $2 \mathrm{~m}^{3} / \mathrm{s}$ ) and agricultural efficiency (i.e. 16\%) and sewage collection networks development (i.e. $45 \%$ increasing of the refinery capacity), and implementing artificial recharge

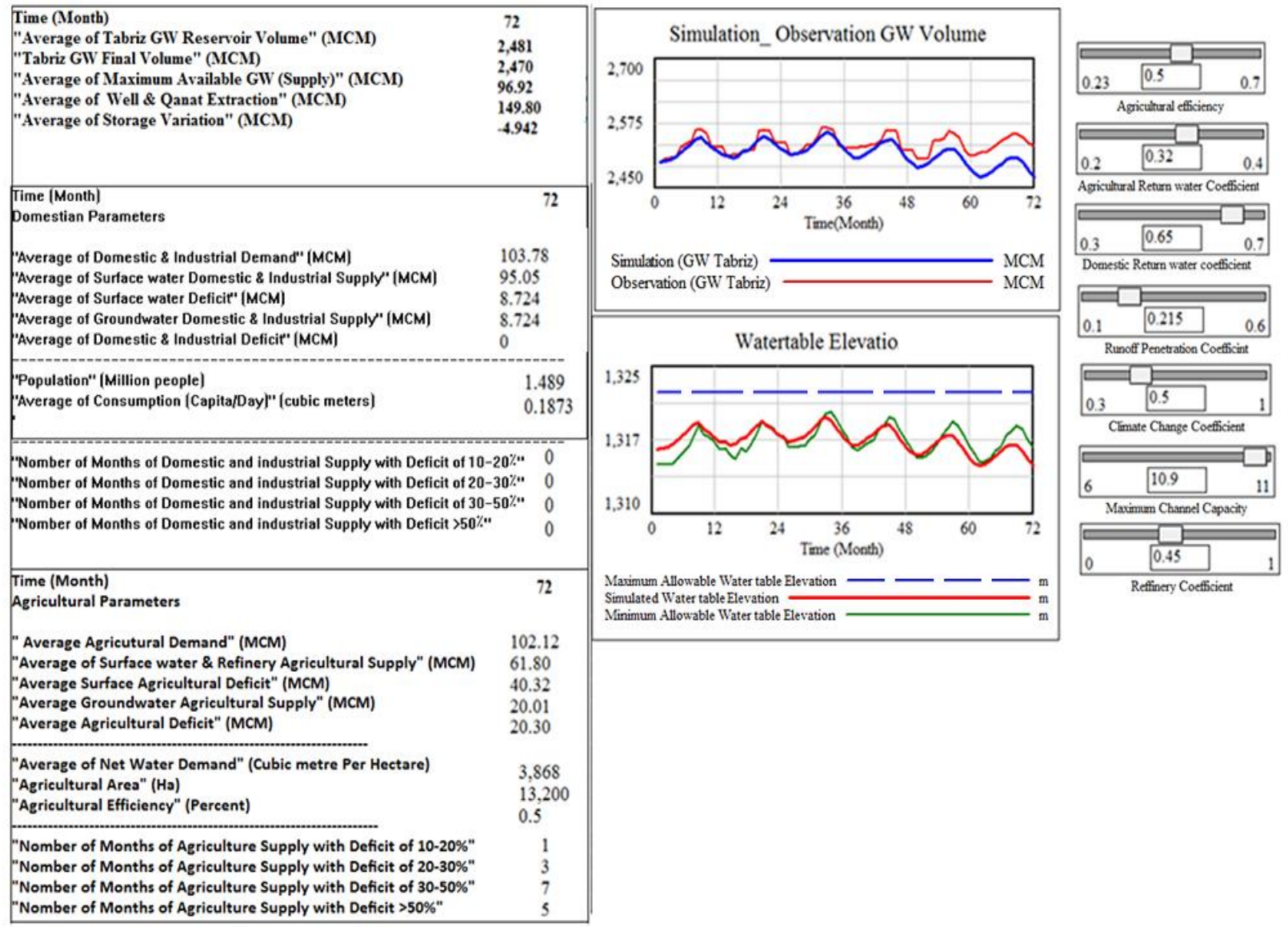

Figure f. The simulation results of fifth scenario: The simulation results of third scenario: Increasing allocation of surface water (i.e. $2 \mathrm{~m}^{3} / \mathrm{s}$ ) and agricultural efficiency (i.e. 16\%) and sewage collection networks development (i.e. $45 \%$ increasing of the refinery capacity), and feeding the aquifer by artificial recharge and $50 \%$ decreasing of the current precipitation (i.e. climatic change), and their effects on aquifer storage and parameters related to agricultural, domestic and industry consumptions. 